Research paper

\title{
Poly(anhydride) nanoparticles containing cashew nut proteins can induce a strong Th1 and Treg immune response after oral administration
}

\author{
Marcela Araújo Pereira ${ }^{\mathrm{a}}$, Juliana de Souza Rebouças ${ }^{\mathrm{b}}$, Rafaela de Siqueira Ferraz-Carvalho ${ }^{\mathrm{a}}$, \\ Inés Luis de Redín ${ }^{c}$, Priscila Valera Guerra ${ }^{\mathrm{d}}$, Carlos Gamazo ${ }^{c}$, Claudia Ida Brodskyn ${ }^{\mathrm{d}}$, \\ Juan M. Irache ${ }^{\mathrm{c}, *}$, Nereide Stela Santos-Magalhães ${ }^{\mathrm{a}}$ \\ ${ }^{a}$ Immunopathology Keizo-Asami Laboratory, LIKA, Federal University of Pernambuco, Recife, Brazil \\ ${ }^{\mathbf{b}}$ Institute of Biological Sciences, University of Pernambuco, Recife, Brazil \\ ${ }^{c}$ Nanomedicines and Vaccines (NANO-VAC) Research Group, University of Navarra, Pamplona, Spain \\ ${ }^{\mathrm{d}}$ Laboratory of Parasite-host Interaction and Epidemiology, Gonçalo Moniz Institute, Oswaldo Cruz Foundation (FIOCRUZ), Salvador, Brazil
}

\section{A R T I C L E I N F O}

\section{Keywords:}

Nanoparticles

Food allergy

Cashew nut

Oral

Immunization

\begin{abstract}
A B S T R A C T
Cashew nut allergy is the second most commonly reported tree nut allergy. Traditional allergen immunotherapy presents several clinical drawbacks that can be reduced by using nanoparticles-based allergen-delivery systems, modulating the immune response towards a protective one. In this context, the goal of this work was to assess the potential of poly(anhydride) nanoparticles (NP) for cashew nut oral immunization. Cashew nut allergens-loaded nanoparticles (CNE-NP) were prepared by solvent displacement method. After nanoparticles characterization, oral immunomodulation ability was evaluated in BALB/c mice. Our results demonstrated that CNE-NP induced a higher Th1/Th2 ratio in comparison with animals immunized with free cashew nut proteins. Indeed, a decrease in splenic Th2 cytokines (IL-4, IL-5, and IL-13), and an enhancement of pro-Th1 (IL-12 and IFN- $\gamma$ ) and regulatory (IL-10) cytokines was observed. Furthermore, mice orally immunized with CNE-NP presented an increased expansion of $\mathrm{CD}^{+}{ }^{+} \mathrm{T}$ regulatory cells, such as $\mathrm{CD} 4{ }^{+} \mathrm{Foxp}^{+}$and $\mathrm{CD} 4^{+} \mathrm{LAP}^{+}$, in the mesenteric lymph nodes. In conclusion, oral immunization with a single dose of poly(anhydride) nanoparticles loaded with cashew nut proteins leaded to a pro-Th1 and Treg immune response. Furthermore, their immunomodulatory properties could be introduced as a new approach for management of cashew nut allergy.
\end{abstract}

\section{Introduction}

Food allergy is defined as an adverse immunological response resulting from consumption or exposure to a given food [1]. Recent prevalence studies have shown that 4 to $-8 \%$ of young children and 2 to $-4 \%$ of adults, in developed countries, have true food allergies [2]. It's estimated that 220-520 million people, globally, may suffer from food allergy.

Tree different types of nuts are included in the "big eight" food groups responsible for food allergies, including cashew nut (Anacardium occidentale). In fact, and in accordance with the Food Allergy and Anaphylaxis Network (FAAN), cashew nut would be the responsible for the second most common tree nut allergy [3]. Importantly, cashew nut seeds can cause severe reactions and present cross reactivity with $25-50 \%$ of peanut allergic patients [4]. In addition, with their global popularity and increased use in snack foods and as an ingredient in a variety of processed foods, the risk of inadvertent exposure to cashew nut seeds is growing fast [5].

Over the years, at least three cashew nut proteins have been reported as potential allergens, known for their sensitizing potential and ability to induce allergic reactions: Ana o 1 [6], Ana o 2 [7] and Ana o 3 [8]. Despite of the high potential to produce allergic reactions, there is no effective treatment available to cashew nut allergy. Auxiliary medication is available to relief allergy symptoms, using antihistamines and also adrenaline to decrease the life-threatening reactions. However, the only safe 'therapy' is the avoidance of foods to which the individual is sensitized, which does not exclude the accidental exposure when foods are either cross-contaminated with allergenic foods, or simply incorrectly described or labelled.

Clinically, allergen-specific conventional immunotherapy (SIT) is able to modify the allergic reaction and induce allergen tolerance by multiple administrations of increased doses of sensitizing allergens,

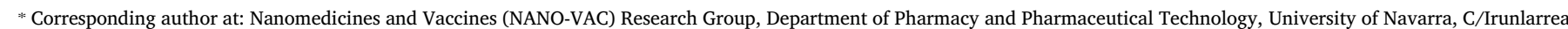
1, 31008 Pamplona, Spain.

E-mail address: jmirache@unav.es (J.M. Irache). 
through subcutaneous or intradermal routes [9].. However, SIT have several limitations which may hinder the effectiveness of the treatment [10]. For instance, SIT requires long-term treatments and, as a consequence, patient adherence is a key factor. In addition, subcutaneous or intradermal injections may be associated with local allergic reactions, even anaphylaxis, and, therefore, SIT cannot be applied in highly sensitized patients [11]. Considering these risks, novel approaches are being investigated, including the use of new adjuvants [12].

Administered orally, they offer protection against the premature degradation of the cargo and may be effective to reduce the number of administrations as well as the duration of the treatment $[13,14]$. This would be directly related to the capability of these nanoparticles to minimize the exposure of the allergen to IgE and, thus, its arrival to mast cells and the occurrence of adverse reactions $[15,16]$.

In the recent past, the use of poly(anhydride) nanoparticles, based on Gantrez $^{\circledast}$ AN, have been proposed for allergen immunotherapy. These nanoparticles have demonstrated their potential with different allergens, including peanut proteins [13,18] and Lollium perenne [18], due to their capability to induce protective immune responses associated with an increased Th1 profile [19]. In addition, these nanoparticles possess bioadhesive properties within the gut mucosa, a key factor for induction of strong mucosal immune responses after oral administration $[20,21]$. Besides, oral delivery is offered as an option to avoid the risky needle use in classical inoculations [20].

In this way, the aim of this work was to design and evaluate poly (anhydride) nanoparticles containing cashew nut allergens for oral mucosal immunization. In vitro and in vivo experiments were performed to evaluate the immunomodulatory capacity of this formulation in view of oral immunotherapy.

\section{Material and methods}

\subsection{Chemicals}

Cashew nut extract (CNE) containing cashew nut proteins were obtained from Diater Laboratories (Madrid, Spain). Poly(methylvinylether-co-maleic anhydride) (PVM/MA), Gantrez ${ }^{\circledR}$ AN 119 (MW 200,000), was kindly provided by Ashland, Inc. 2,20-Azino-bis(3ethylbenzothiazoline-6-sulfonic acid) diammonium salt (ABTS), PBS containing $0.05 \%$ Tween 20 (PBS-T) and immunoconjugates (mouse anti-human/IgE, goat anti-mouse/IgG/conjugated with horseradish peroxidase, and mouse anti-human/IgE/conjugated with horseradish peroxidase) were purchased from Sigma (Madrid, Spain). Mouse enzyme-linked immunosorbent assay (ELISA) kits were purchased from BD Biosciences (San Diego, CA, USA). AgraQuant (2 - 60 ppm) were purchased form Romer Labs Diagnostic (Tulln, Austria). The rainbowcolored protein molecular weight marker (RPN756) was purchased from Amersham Pharmacia Biotech (Freiburg, Germany). Nitrocellulose membrane and ECL TM Prime western blotting detection reagent was provided by GE Healthcare (Illinois, USA). Float-A-Lyzer 300,000 M.W.C.O. was purchased from Spectrum Labs (California, USA). Mannitol was supplied by Guinama (Valencia, Spain). 4-chloro-1naphtol and all other chemicals used were of reagent grade and obtained from Merck (Barcelona, Spain). Sandwich enzyme-linked immunosorbent assay kit (ELISA) (AgraQuant ${ }^{\circledR}$ Anacardo 2-60 ppm) purchased from Romer Labs Diagnostic $\mathrm{GmbH}^{\circledR}$ for cashew nut allergy (Tulln, Austria).

\subsection{Preparation of poly(anhydride) nanoparticles}

Poly(anhydride) nanoparticles containing CNE (CNE-NP) were prepared by the solvent displacement method, previously described [17], with some modifications. Initially, CNE was dispersed in $100 \mu \mathrm{L}$ of ultrapure water ( $\mathrm{pH}$ 3.0) by ultrasonication $\left(\right.$ Microson $^{\mathrm{TM}}$ ) for $1 \mathrm{~min}$ and resuspended in $1 \mathrm{~mL}$ acetone. The CNE dispersion was added to $100 \mathrm{mg}$ poly(anhydride) polymer previously solubilized into $4 \mathrm{~mL}$ acetone. Pre- formulation studies were performed in order to optimize the CNE payload. Thus, several batches of nanoparticle formulations were prepared to determine the optimal amount of CNE (3.0, 4.5, 6.0, 7.5 and $9.0 \mathrm{mg})$ and the incubation time of polymer and CNE (15, 30, 45 and $60 \mathrm{~min}$ ). After incubation at room temperature (RT), the polymer mixture containing the $\mathrm{CNE}$ was precipitated by the addition of a mixture of ethanol and ultrapure water $(1: 1 \mathrm{v} / \mathrm{v})$. Then, the organic solvents were eliminated under reduced pressure (Buchi ${ }^{\circledR}$ R-144, Switzerland). The nanoparticle suspensions were purified twice in ultrapure water and submitted to ultracentrifugation at $28,000 \mathrm{~g}$ for $20 \mathrm{~min}$. Finally, nanoparticle formulations were lyophilized for $48 \mathrm{~h}$ using an aqueous solution containing mannitol (5\% w/v) as cryoprotectant (Genesis 12EL, VirTis, USA). Empty nanoparticles (NP) were prepared in the same way as described above but in the absence of CNE.

\subsection{Characterization of poly(anhydride) nanoparticles}

\subsubsection{Size and zeta potential}

Size and surface charge (zeta potential) of nanoparticle formulations (NP and CNE-NP) were determined by photon correlation spectroscopy (PCS) and electrophoretic laser Doppler anemometry, respectively, using a Zeta master analyzer system (Malvern, UK). Samples were diluted with ultrapure water or $\mathrm{KCl} 0.1 \mathrm{mM}$ for measurements of size and zeta potential, respectively. All analyses were performed in triplicate using a fixed angle of $90^{\circ}$ at $25^{\circ} \mathrm{C}$. The mean particle size was expressed as the mean diameter in nanometers ( $\mathrm{nm}$ ) and the mean surface charge as $\mathrm{mV}$.

\subsubsection{Protein loading and encapsulation efficiency}

In order to quantify the amount of cashew nut protein extract (CNE) incorporated in the nanoparticles, $10 \mathrm{mg}$ lyophilized nanoparticles were digested in $\mathrm{NaOH} 0.1 \mathrm{M}$ by shaking the mixture at $37^{\circ} \mathrm{C}$ for $1 \mathrm{~h}$. The protein content was then measured by a sandwich enzyme-linked immunosorbent assay kit (ELISA) for cashew nut detection following manufacturer's instructions. Each sample was assayed in triplicate. From ELISA data, the payload of CNE in nanoparticles was expressed as the amount of protein $(\mu \mathrm{g})$ per mg nanoparticles, whereas the encapsulation efficiency was expressed in percentage.

\subsubsection{Yield}

The amount of polymer transformed into nanoparticles was determined by gravimetry following a procedure previously described [18].

\subsubsection{Structural integrity and antigenicity of encapsulated cashew nut proteins}

To identify and evaluate the profile of free or encapsulated cashew nut allergens in the nanoparticles, capillary gel electrophoresis (CGE) was carried out using an Experion ${ }^{\mathrm{TM}}$ Automated Electrophoresis System (Bio Rad, Hercules, USA) [21]. The data obtained were processed using the software Experion ${ }^{\mathrm{TM}}$ System. Samples of purified cashew nut proteins were used as controls. All samples were evaluated after treatment with 2-mercaptoethanol and heated at $100{ }^{\circ} \mathrm{C}$. Then, the samples were treated following the protocol of the Experion ${ }^{\mathrm{TM}}$ Pro260 Analysis Kit. The samples and controls were then loaded into the chip and analyzed. The results were obtained as densitometric bands in a virtual gel identified as different peak sizes expressed in kilodaltons $(\mathrm{kDa})$ in the ladder control band.

In order to evaluate the effects of the manufacturing process of nanoparticles on the integrity and antigenicity of cashew nut proteins, SDS-PAGE and immunoblotting were performed as previously described [17]. Briefly, $10 \mathrm{mg}$ of either CNE or lyophilized nanoparticles containing cashew nut proteins (CNE-NP) were resuspended in $1 \mathrm{~mL}$ ultrapure water and centrifuged $\left(28,000 \mathrm{~g}, 20 \mathrm{~min}, 4^{\circ} \mathrm{C}\right)$. Then, the sediment was dissolved in $2 \mathrm{~mL}$ of acetone/dimethylformamide (3:1 by vol.) and stored for $1 \mathrm{~h}$ at $-80^{\circ} \mathrm{C}$. Samples were then centrifuged 
Table 1

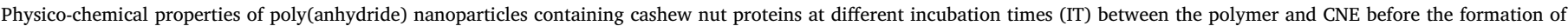
nanoparticles. Experiments were carried out at a CNE-to-polymer ratio of 0.03 . Data expressed as mean \pm standard deviation, $\mathrm{n}=3$.

\begin{tabular}{|c|c|c|c|c|c|c|c|}
\hline & IT (min) & Size (nm) & PDI & Zeta Potential (mV) & Payload ( $\mu \mathrm{g} / \mathrm{mg})$ & $\mathrm{EE}(\%)$ & Yield (\%) \\
\hline $\mathrm{NP} / 0$ & 0 & $184 \pm 2$ & $0.21 \pm 0.00$ & $-50.3 \pm 2.4$ & - & - & $80 \pm 3$ \\
\hline CNE-NP/15 & 15 & $190 \pm 2$ & $0.22 \pm 0.00$ & $-42.9 \pm 0.6$ & $13 \pm 1.2$ & $29 \pm 1.1$ & $83 \pm 1$ \\
\hline CNE-NP/30 & 30 & $194 \pm 1$ & $0.24 \pm 0.01$ & $-46.1 \pm 0.8$ & $32 \pm 3.8$ & $80 \pm 4.3$ & $89 \pm 4$ \\
\hline CNE-NP/45 & 45 & $211 \pm 1$ & $0.24 \pm 0.00$ & $-40.6 \pm 0.4$ & $26 \pm 3.1$ & $70 \pm 6.0$ & $91 \pm 3$ \\
\hline CNE-NP/60 & 60 & $187 \pm 1$ & $0.22 \pm 0.01$ & $-38.5 \pm 0.4$ & $22 \pm 2.9$ & $53 \pm 2.5$ & $88 \pm 3$ \\
\hline
\end{tabular}

PDI: polydispersity index; EE: encapsulation efficiency.

Table 2

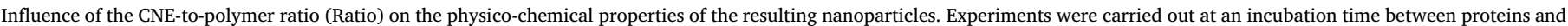
the polymer of $30 \mathrm{~min}$. Data expressed as mean \pm standard deviation, $\mathrm{n}=3$.

\begin{tabular}{|c|c|c|c|c|c|c|c|}
\hline & Ratio & Size (nm) & PDI & Zeta potential (mV) & Payload ( $\mu \mathrm{g} / \mathrm{mg}$ ) & $\mathrm{EE}(\%)$ & Yield (\%) \\
\hline CNE-NP/3.0 & 0.03 & $194 \pm 1$ & $0.24 \pm 0.01$ & $-46.1 \pm 0.8$ & $32 \pm 3.8$ & $80 \pm 4.3$ & $89 \pm 4$ \\
\hline CNE-NP/4.5 & 0.045 & $203 \pm 1$ & $0.23 \pm 0.03$ & $-41.5 \pm 0.4$ & $35 \pm 4.3$ & $53 \pm 2.7$ & $91 \pm 1$ \\
\hline CNE-NP/6.0 & 0.06 & $239 \pm 5$ & $0.28 \pm 0.03$ & $-38.1 \pm 0.3$ & $55 \pm 5.8$ & $62 \pm 3.9$ & $91 \pm 2$ \\
\hline CNE-NP/7.5 & 0.075 & $264 \pm 6$ & $0.27 \pm 0.01$ & $-36.4 \pm 0.3$ & $48 \pm 1.0$ & $35 \pm 3.2$ & $89 \pm 2$ \\
\hline CNE-NP/9.0 & 0.09 & $574 \pm 11$ & $0.37 \pm 0.01$ & $-34.8 \pm 0.3$ & $49 \pm 3.6$ & $39 \pm 4.6$ & $75 \pm 2$ \\
\hline
\end{tabular}

PDI: polydispersity index; EE: encapsulation efficiency.

$\left(28,000 \mathrm{~g}, 20 \mathrm{~min}\right.$, at $\left.4{ }^{\circ} \mathrm{C}\right)$ and the pellet was washed with $1 \mathrm{~mL}$ acetone and stored at $-80^{\circ} \mathrm{C}$ for $30 \mathrm{~min}$. After centrifugation under the same conditions, pellets were resuspended in a $\mathrm{pH} 6.8$ buffer solution of Tris-HCl $62.5 \mathrm{mM}$ (containing glycerol (10\%), sodium dodecyl sulfate (2\%), 2-mercaptoethanol (5\%) and bromophenol blue (0.05\%)), and boiled for $10 \mathrm{~min}$. SDS-PAGE was performed using discontinuous gels of $12 \%$ acrylamide. The apparent molecular mass of cashew nut proteins was determined by comparison with standard molecular weight markers.

For antigenicity evaluation, cashew nut proteins previously separated by electrophoresis, were transferred from the gel to a nitrocellulose membrane $(0.45 \mu \mathrm{m})$ using a semidry blotting system operating at $0.8 \mathrm{~mA} / \mathrm{cm}^{2}$ for $60 \mathrm{~min}$ (Trans-Blot ${ }^{\circledR} \mathrm{SD}$ Transfer Cell, BioRad, Hercules, USA). After the blocking of protein-binding sites with a solution of 5\% defatted milk in 1\% Tween 20 TBS (tris buffer solution) (RT, $60 \mathrm{~min}$ ), the membranes were incubated with sera from cashew nut allergic patients (1:5 with 1\% TBS-Tween 20) and maintained overnight at $4^{\circ} \mathrm{C}$. Primary antibody (mouse anti-human IgE, 1:1000, Sigma-Aldrich, Madrid, Spain) was then added and incubated at $4{ }^{\circ} \mathrm{C}$ overnight. Secondary antibody (peroxidase - conjugate - Fc specific goat anti-mouse IgG 1:10,000, Sigma) were added and incubated at RT for $1 \mathrm{~h}$. Finally, membranes were extensively washed and ECL ${ }^{\mathrm{TM}}$ Prime Western Blotting Detection Reagent (GE Healthcare, Illinois, USA) was used as revealing solution. Serum from non-allergic patient was used as a negative control.

\subsubsection{Differential scanning calorimetry}

Thermograms of CNE, NP and CNE-NP were recorded by heating samples from $35^{\circ} \mathrm{C}$ to $250{ }^{\circ} \mathrm{C}$ at a heating rate of $10^{\circ} \mathrm{C} / \mathrm{min}$ using an empty aluminum pan as the reference. Powdered samples were accurately weighed $(5 \mathrm{mg})$ in aluminum pans, sealed and subjected to differential scanning calorimetry (DSC) under nitrogen flow using a Perkin Elmer Pyris 6 DSC equipment.

\subsubsection{X-ray diffraction}

X-ray diffraction spectra of CNE, NP and CNE-NP were recorded at room temperature using a Pro Expert X-ray diffractometer (Philips-FEI, Netherlands), with nickel filtered $\mathrm{Cu} \mathrm{K} \alpha$ radiation operated at a voltage of $3 \mathrm{kV}, 5 \mathrm{~mA}$ current, $4^{\circ} / \mathrm{min}$ scanning speed, and $5-40^{\circ}(2 \theta)$ range.

\subsubsection{Fourier transform infrared spectrometry}

The interaction between polymer and cashew nut protein extract was evaluated by Fourier transform infrared spectrometry (FTIR). Thus, FTIR spectra of CNE and lyophilized nanoparticles (NP and CNE-NP) were performed. Samples were prepared in $\mathrm{KBr}$ disks and transmittance was measured from 500 to $4000 \mathrm{~cm}^{-1}$ using a FT/IR-4600 spectrometer (Jasco, Maryland, USA). The data were processed (Origin 8, OriginLab Northampton, USA) and final graphs were plotted. The measurements were carried out in triplicate.

\subsubsection{In vitro stability in gastrointestinal fluids}

The stability of CNE-NP in simulated gastrointestinal fluids was evaluated by measuring the turbidity of the medium and the particle size of nanoparticles over time. Briefly, $6 \mathrm{mg}$ lyophilized nanoparticles were resuspended in $2 \mathrm{~mL}$ simulated gastric (SGF, $\mathrm{pH}$ 1.2) or intestinal fluids (SIF, pH 6.8), supplemented with Tween $20(1 \% \mathrm{w} / \mathrm{v})$ and aliquots of $300 \mu \mathrm{L}$ of each sample transferred into microplate wells. The turbidity of the samples was evaluated by measuring the absorbance at $405 \mathrm{~nm}$ over time ( 0 to $-2 \mathrm{~h}$ for SGF and 2 to $-10 \mathrm{~h}$ for SIF). If necessary, samples were diluted to obtain the same initial absorbance in all cases at the beginning of the study. All measurements were performed in triplicate. Results were expressed as percentage of absorbance reduction (\% reduction) vs time.

\subsubsection{In vitro release study}

Release studies of CNE from nanoparticles were performed under "sink" conditions, using simulated gastric (SGF) and intestinal fluids (SIF) supplemented with Tween $20(1 \% \mathrm{w} / \mathrm{v})$. For these purpose, FloatA-Lyzer devices with a MWCO of $300 \mathrm{kDa}$ (Spectrum Labs, CA, USA) were used [22]. The device was filled with $5 \mathrm{~mL}$ of a suspension of nanoparticles $(20 \mathrm{mg}$ ) in SGF and, then, placed into a vessel containing $660 \mathrm{~mL}$ SGF. The vessel was maintained under magnetic agitation and $200 \mu \mathrm{L}$ samples were withdrawn at fixed time intervals and replaced with equal volume of SGF. After two hours of incubation in this gastric fluid, the device was placed into a second vessel with $660 \mathrm{~mL}$ SIF for more $22 \mathrm{~h}$, to complete $24 \mathrm{~h}$ of release. Again, at fixed times, $200 \mu \mathrm{L}$ were withdrawn and replaced with fresh SIF. The amount of CNE released from nanoparticles was quantified using ELISA technique as described above.

\subsection{Macrophage assays}

\subsubsection{Cell viability}

Macrophages RAW 264.7 (ATCC-TIB-71) from murine tumors 

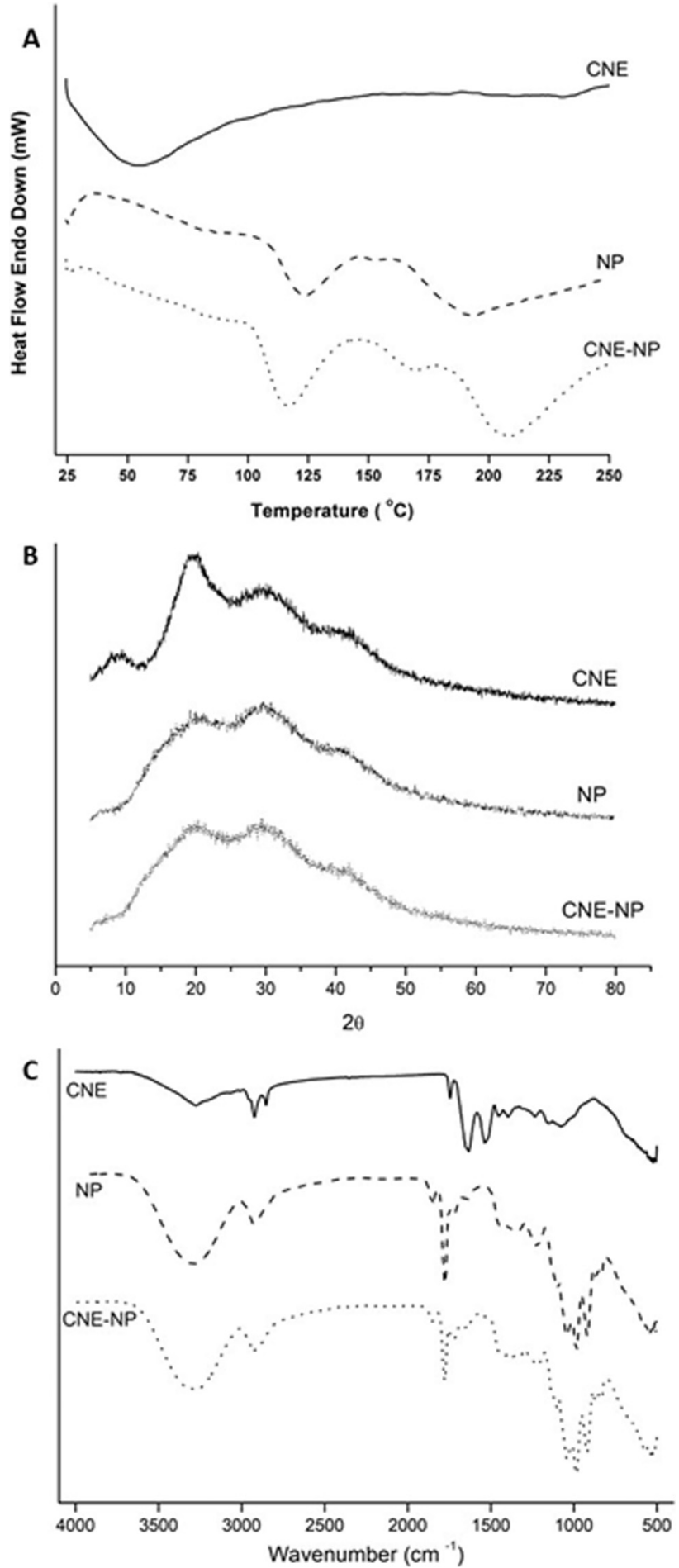

Fig. 1. Physicochemical comparison of cashew nut proteins in free form (CNE) or loaded into poly(anhydride) nanoparticles (CNE-NP). Empty nanoparticles (NP) are also included as a control. (A) DSC thermograms; (B) X-ray powder diffractograms; (C) Fourier-transformed infrared spectra.

(leukemia) induced by the Abelson leukemia virus were cultured and maintained in DMEM medium (Gibco, California, USA) containing 10\% fetal bovine serum and $1 \%$ antibiotic solution, $(1.000 \mathrm{U} / \mathrm{mL}$ penicillin/ streptomycin) (Invitrogen, California, USA).

The evaluation of cell viability was performed using the 3-(4,5-dimethylthiazolyl-2)-2,5-diphenyltetrazolium bromide (MTT) assay. Raw 264.7 macrophages $\left(5 \times 10^{5}\right.$ cells/well) were incubated with samples at different concentrations for $24 \mathrm{~h}$, at $37^{\circ} \mathrm{C}$, in a humidified

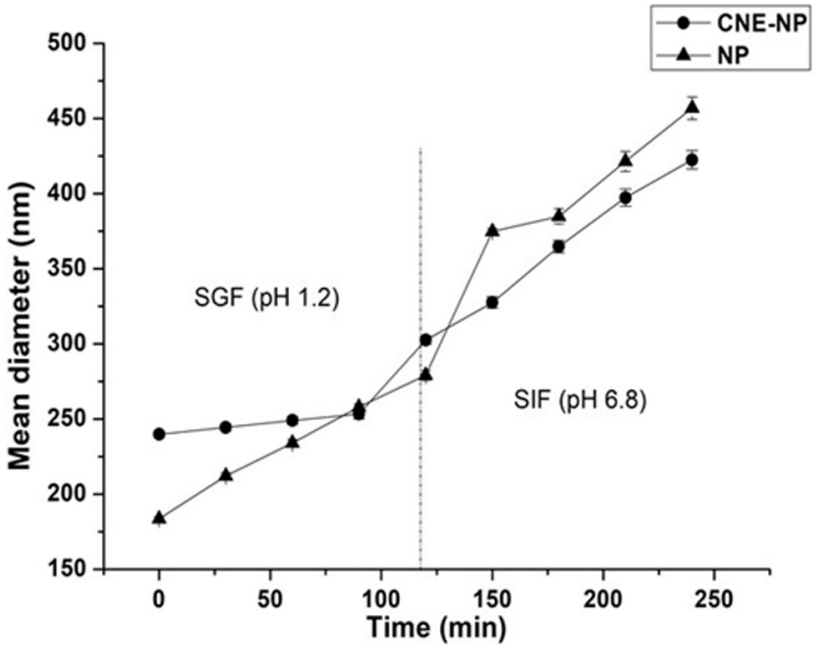

Fig. 2. In vitro stability studies of poly(anhydride) nanoparticles in simulated gastric (SGF) and intestinal (SIF) fluids. Samples containing cashew proteins loaded into poly (anhydride) nanoparticles (CNE-NP) and empty nanoparticles (NP) were incubated in SGF $(0-120 \mathrm{~min})$ followed by incubation in SIF. Data are expressed as mean $\pm \operatorname{SD}(n=3)$.

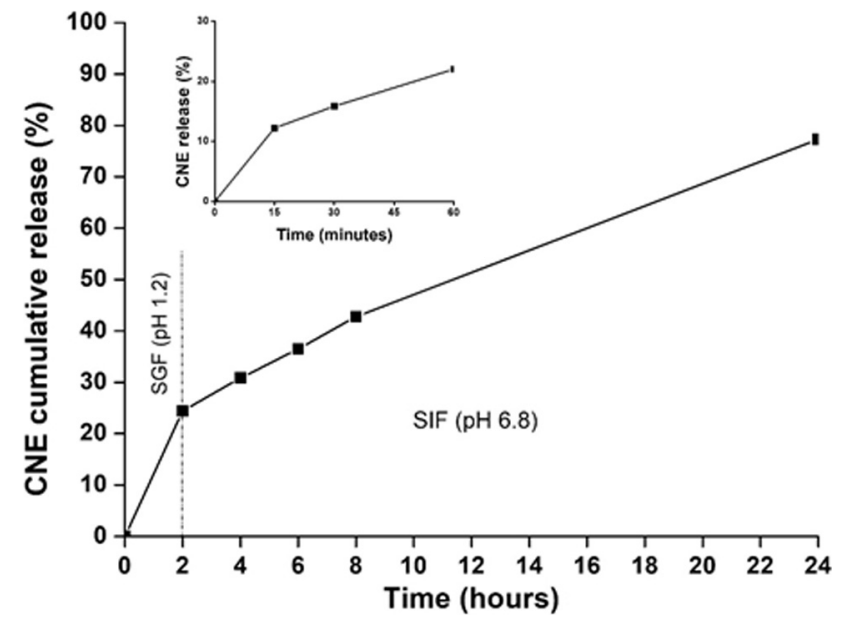

Fig. 3. In vitro release profiles of cashew nut proteins (CNE) from poly(anhydride) nanoparticles. Loaded nanoparticles were incubated for $24 \mathrm{~h}$ in simulated gastric fluid (SGF) and simulated intestinal fluid (SIF) medium at $37^{\circ} \mathrm{C}$. The insert shows the amount of CNE released from nanoparticles during the first $60 \mathrm{~min}$ of incubation in SGF. Data are expressed as mean $\pm \operatorname{SD}(n=3)$.

atmosphere with $5 \% \mathrm{CO}_{2}$. After incubation, the supernatant was removed and MTT $(1 \mathrm{mg} / \mathrm{ml}$ in DMEM medium supplemented) was added. After $4 \mathrm{~h}$ of incubation, the MTT solution was removed and $50 \mu \mathrm{L}$ DMSO was added to each well. The absorbance of the resulting solution was analyzed by spectrophotometer (Molecular Devices, USA) at $595 \mathrm{~nm}$ [23]. Assays were performed in triplicate and repeated three times. Cell viability (\%) was determined for free CNE $(0-25 \mu \mathrm{g} / \mathrm{mL})$, empty NP (NP, 0-500 $\mu \mathrm{g} / \mathrm{mL})$ and CNE-NP $(0-500 \mu \mathrm{g} / \mathrm{mL})$. All groups were compared to the control group that matches the cells without treatment.

\subsubsection{Macrophage activation}

The analysis of the anti-inflammatory activity of nanoparticle formulations was performed in lipopolysaccharide (LPS)-stimulated murine macrophages (RAW 264.7, American Type Culture Collection, ATCC-TIB-71) [24]. In brief, cells were seeded at a density of $1 \times 10^{6}$ cells per well in 96-well plates. After $24 \mathrm{~h}$ incubation at $37^{\circ} \mathrm{C}$, cells were pretreated with the samples (CNE $5 \mu \mathrm{g} / \mathrm{mL}$; CNE-NP $100 \mu \mathrm{g} / \mathrm{mL}$; NP $100 \mu \mathrm{g} / \mathrm{mL}$ ) for $3 \mathrm{~h}$ before LPS (from Escherichia coli) was added at a final concentration of $100 \mathrm{ng} / \mathrm{mL}$. After further $24 \mathrm{~h}$ of incubation, the 


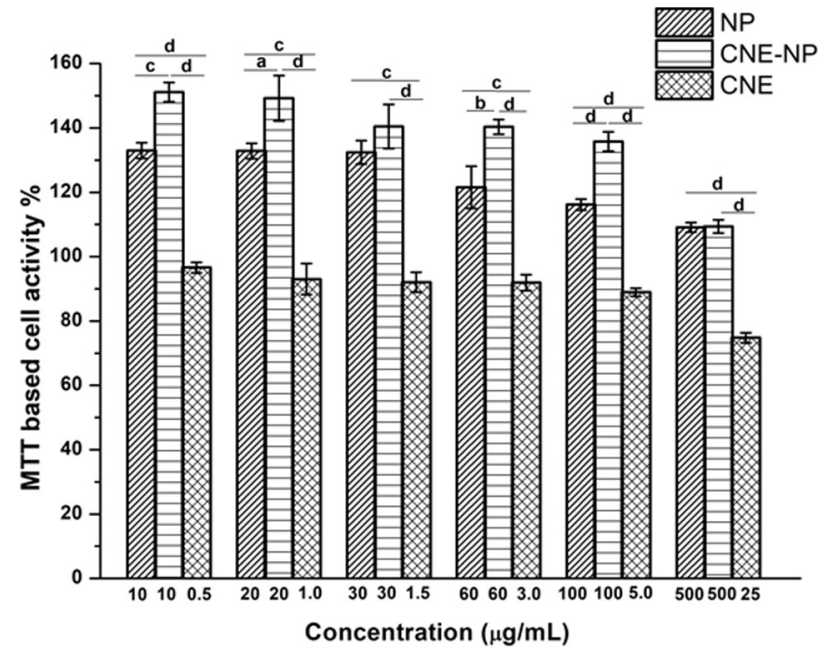

Fig. 4. Viability of Raw 264.7 macrophages after exposure to different concentrations of free cashew nut extract (CNE), empty nanoparticles (NP) and CNE-loaded nanoparticles (CNE-NP) for $24 \mathrm{~h}$ determined by MTT assay. Data are expressed as mean \pm SD; $n=5$. " $\mathrm{p}<0.05 ;{ }^{* * *} \mathrm{p}<0.01 ;{ }^{* * * *} \mathrm{p}<0.001 ;{ }^{* * * * *} \mathrm{p}<0.0001$.
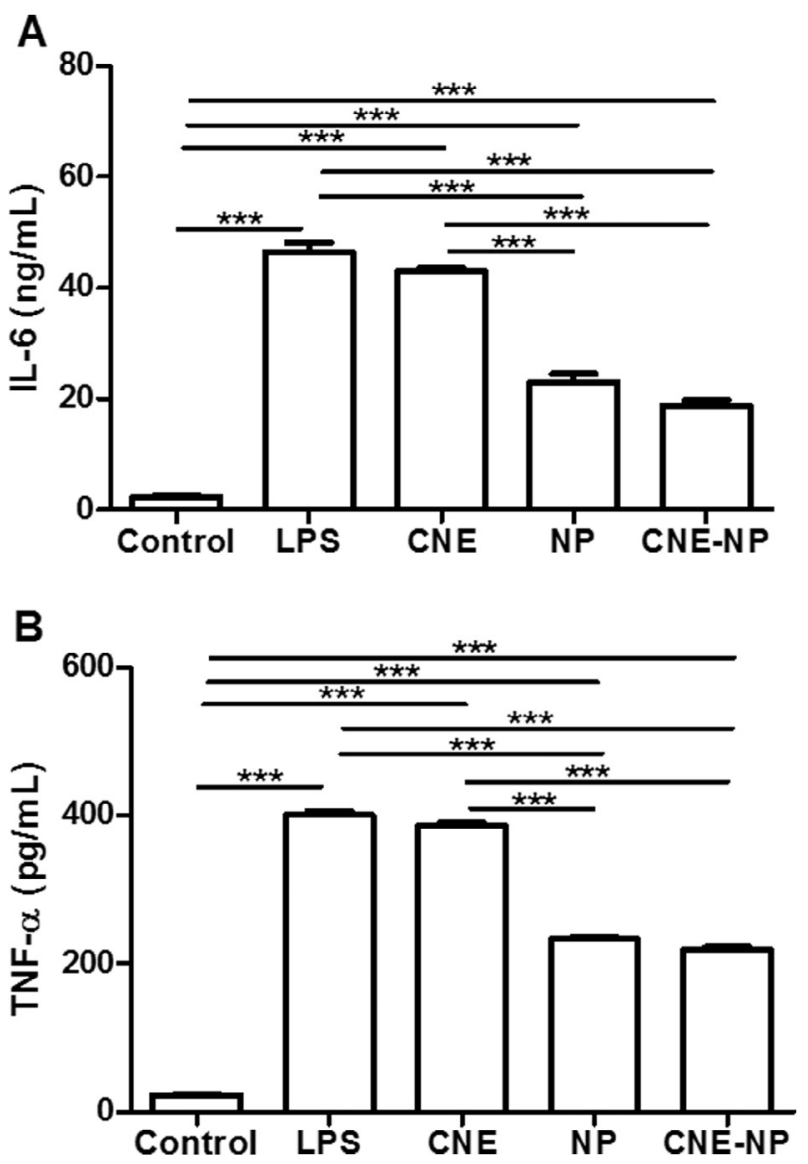

Fig. 5. Effect of cashew nut extract, either free or encapsulated into nanoparticles, on the release of IL-6 (A) and TNF- $\alpha$ (B) by Raw cells. CNE ( $5 \mu \mathrm{g} / \mathrm{mL})$; empty nanoparticles (NP, $100 \mu \mathrm{g} / \mathrm{mL})$, CNE-NP $(100 \mu \mathrm{g} / \mathrm{mL})$. Untreated cells were used as a negative control. Data are expressed as mean $\pm \mathrm{SD} ; n=5 . \quad$ " $\mathrm{p}<0.05 ; \quad \stackrel{* * *}{\mathrm{p}}<0.01 ; \quad$ ***k $\mathrm{p}<0.001$; $\mathrm{p}<0.0001$.

medium was removed, centrifuged and stored at $-20{ }^{\circ} \mathrm{C}$ prior to analysis by ELISA. The secretion of TNF- $\alpha$ and IL- 6 by macrophages was analyzed using ELISA kits according to the manufacturer's protocol.

\subsection{In vivo studies}

\subsubsection{Animals}

Experiments were performed in compliance with the regulations of the Ethics Committee of the Gonçalo Moniz Institute, Oswaldo Cruz Foundation - FIOCRUZ in line with the Brazilian legislation on animal experiments (approved protocol 008/2015).

\subsubsection{Oral immunization}

Female BALB/c mice (Gonçalo Moniz Institute, Oswaldo Cruz Foundation-FIOCRUZ/BA, Brazil), 8 weeks old (weight, $20 \pm 1 \mathrm{~g}$ ), were randomly divided into three experimental groups $(n=5-6$ per group): (i) free cashew nut extract, CNE; (ii) empty nanoparticles, NP; and (iii) nanoparticles loaded with cashew nut extract, CNE-NP. Oral immunization was performed by oral gavage with a single dose $(1 \mathrm{mg})$ of either CNE or CNE-NP. A control group of non-immunized mice (control, Ctrl) were also included in the study. Blood samples were weekly collected for serum extraction. Six weeks after immunization, mice were sacrificed and both spleens and mesenteric lymph nodes were extracted.

\subsubsection{Quantification of specific-antibodies}

The presence of CNE-specific antibodies were determined in sera (IgG1, IgG2a and IgE) by indirect enzyme-linked immunosorbent assay (ELISA), as previously described [17]. Measurements were taken in triplicate and included negative controls (no mouse serum sample background and no antigen coating control).

\subsubsection{Cytokine production}

Spleen cells suspensions were obtained and stimulated with cashew nut proteins $(150 \mu \mathrm{g} / \mathrm{ml})$ and concanavalin A $(5 \mu \mathrm{g} / \mathrm{mL}$, as a positive control). Non-stimulate cells were used as negative control. Culture supernatants were analyzed for the presence of cytokines (IL-4, IL-5, IL10, IL-12, IL-13 and IFN- $\gamma$ ) by ELISA [17], using recombinant cytokines as standard controls (BD Pharmingen, San Diego, CA, USA).

\subsubsection{Flow cytometry analysis}

Monoclonal antibodies anti-CD4 (PerCP/Cy5.5), anti-LAP (PE/Cy7) and anti-FoxP3 (eFluor450) were purchased from eBioscience. The biotinylated anti-human LAP (TGF- $\beta$ ) antibody was purchased from R\& D Systems. Surface staining was performed according to standard procedures at density of $1 \times 10^{6}$ cells (isolated from the mesenteric lymph nodes) per well. The samples were analyzed in a FACS Fortesa instrument (BD Biosciences). Results were analysed by FlowJo Software (Tree Star Inc.).

\subsection{Statistical analysis}

Analysis of variance (ANOVA) was employed to analyze the data. When ANOVA indicated a significant difference, the Tukey post hoc test was used to assess the difference between groups. Differences were regarded as statistically significant at $p$ values of $<0.05$. Data are expressed as the mean standard deviation (SD) from independent experiments.

\section{Results and discussion}

\subsection{Optimization of the preparative process of nanoparticles}

In this study, poly(anhydride) nanoparticles loaded with cashew nut allergens were successfully obtained by a solvent displacement method, in order to produce homogeneous batches of nanoparticles and reproducible results. In previous studies, these nanoparticles have demonstrated an important ability to encapsulate different types of protein allergens $[12,13,16]$. Initially, an optimization study was carried out to establish the ideal preparative conditions of CNE-loaded 

Control
CNE
NP
CNE-NP

$\lg \mathrm{G} 1$

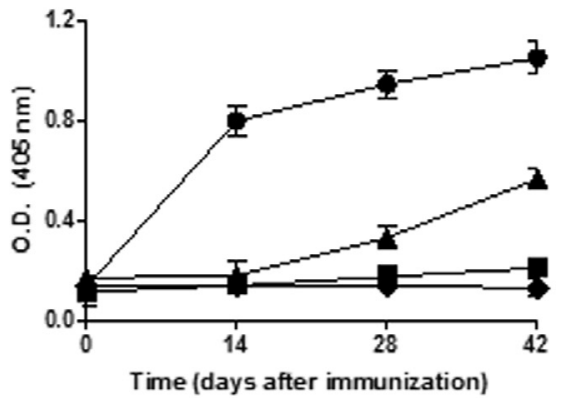

$\lg \mathrm{G} 1$

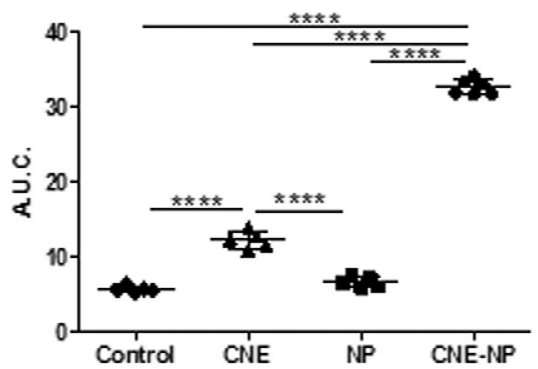

$\lg \mathrm{g} 2 \mathrm{a}$

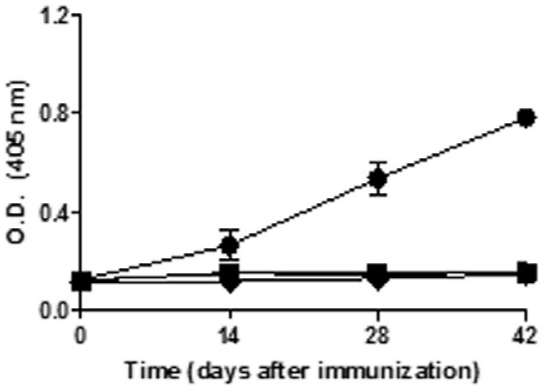

IgG2a

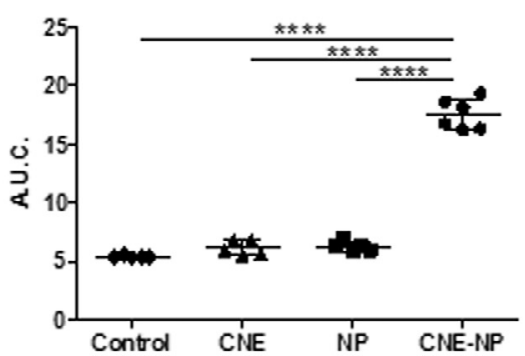

Specific IgE

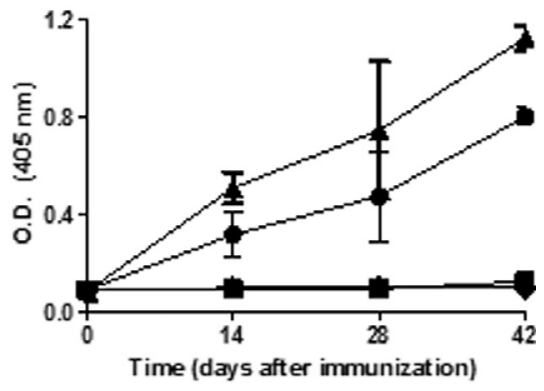

Specific lgE

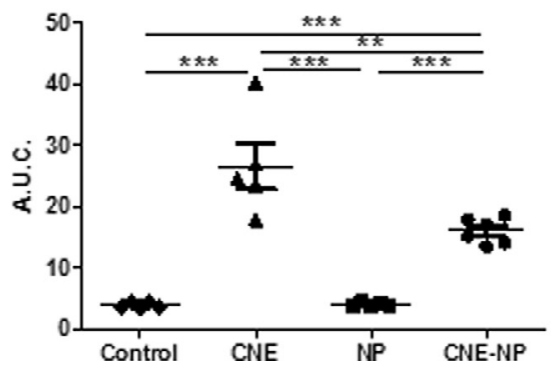

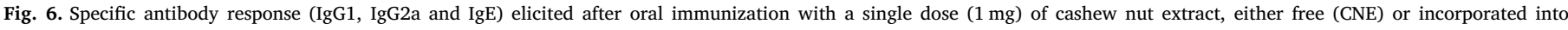

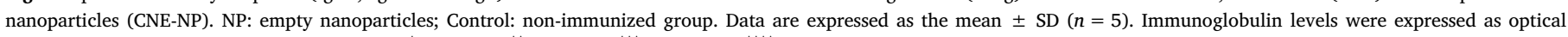
density (OD) and area under the curve (AUC). ${ }^{*} \mathrm{p}<0.05 ;{ }^{* * k} \mathrm{p}<0.01 ;{ }^{* * * *} \mathrm{p}<0.001 ;{ }^{* * * * * *} \mathrm{p}<0.0001$
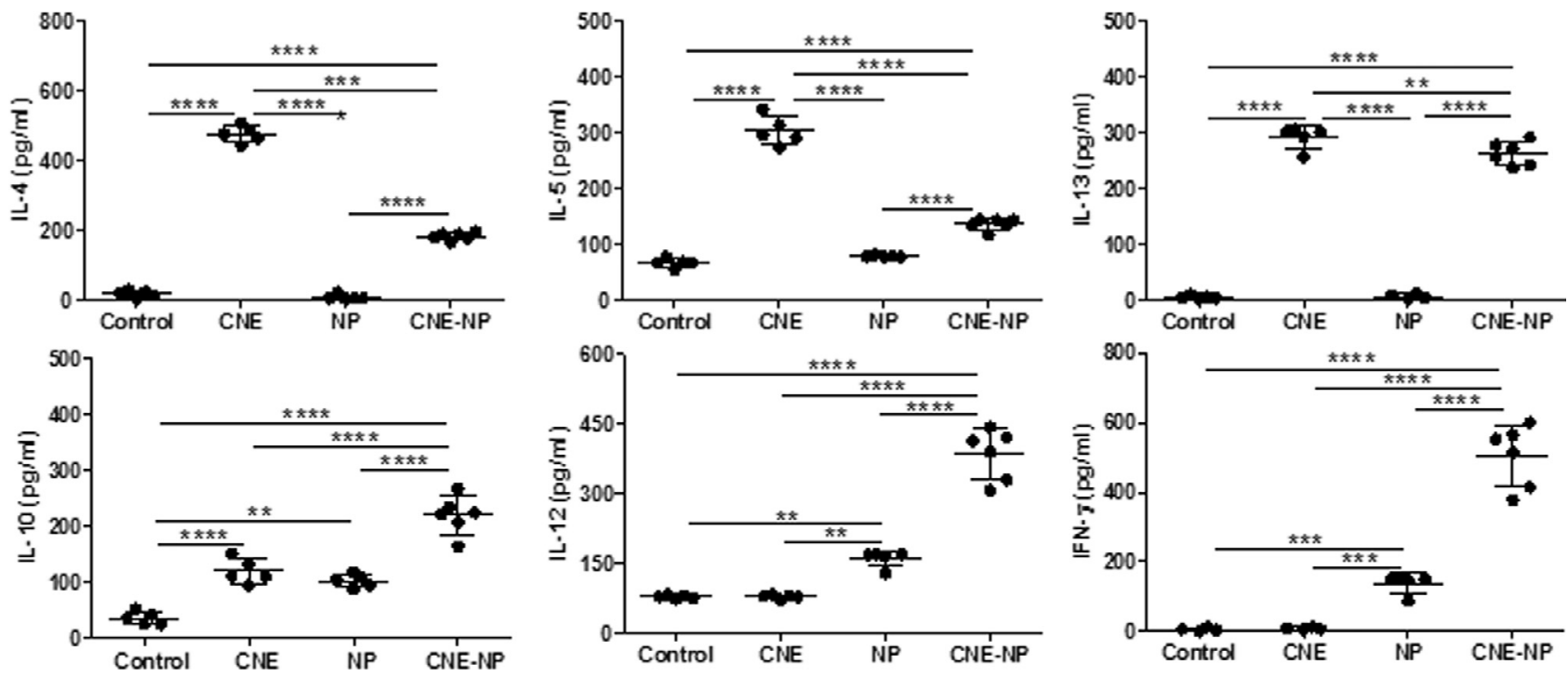

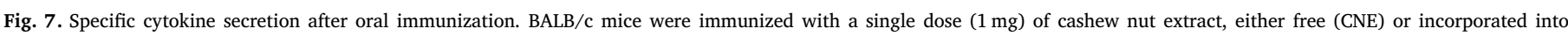

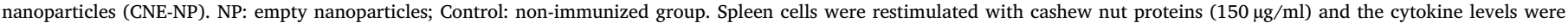
measured by ELISA. Data are expressed as mean $\pm \mathrm{SD}(n=5) .{ }^{*} \mathrm{p}<0.05 ;{ }^{* * *} \mathrm{p}<0.01 ;{ }^{* * * *} \mathrm{p}<0.001 ;{ }^{* * * * *} \mathrm{p}<0.0001$.

nanoparticles. For this purpose, two main parameters were evaluated: the incubation time between CNE and the polymer and the CNE-topolymer ratio. Table 1 summarizes the data obtained during the evaluation of the incubation time between the cashew nut extract and the polymer (at a CNE-to-polymer ratio of 0.03 ) on the physicochemical properties of the resulting nanoparticles. In all cases, the mean diameter was below $220 \mathrm{~nm}$ with a polydispersity index (PDI) of about 0.2, showing no significant changes in function of the incubation time. However, by increasing the incubation time between the polymer and the proteins, the negative charge of the resulting nanoparticles slightly decreased. On the other hand, the incubation time highly influenced the payload of the resulting nanoparticles. Thus, the highest CNE loading was observed when nanoparticles were prepared after $30 \mathrm{~min}$ of incubation of the proteins with the polymer. Similar times of incubation are required to obtain the highest capability of poly(anhydride) nanoparticles to load ovoalbumin [25], Lollium perenne extract [18] or antigenic complexes of Salmonella enteritidis [26]. In our case, and under these experimental conditions (CNE-to-polymer ratio of 0.03 and $30 \mathrm{~min}$ of incubation), the payload was calculated to be around $32 \mu \mathrm{g}$ CNE per mg nanoparticles, with an EE close to $80 \%$.

Table 2 summarizes the effect of the CNE-to-polymer ratio on the characteristics of the resulting nanoparticles. In this case, by increasing 


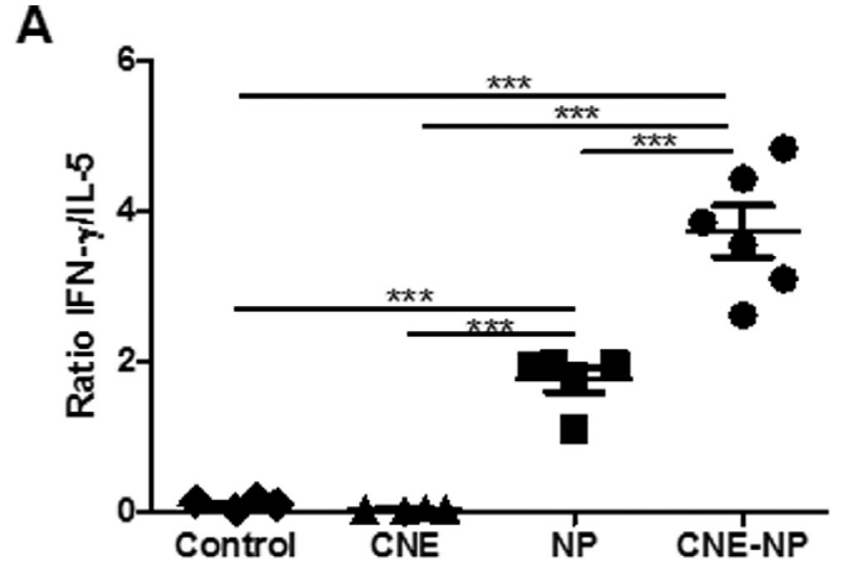

B

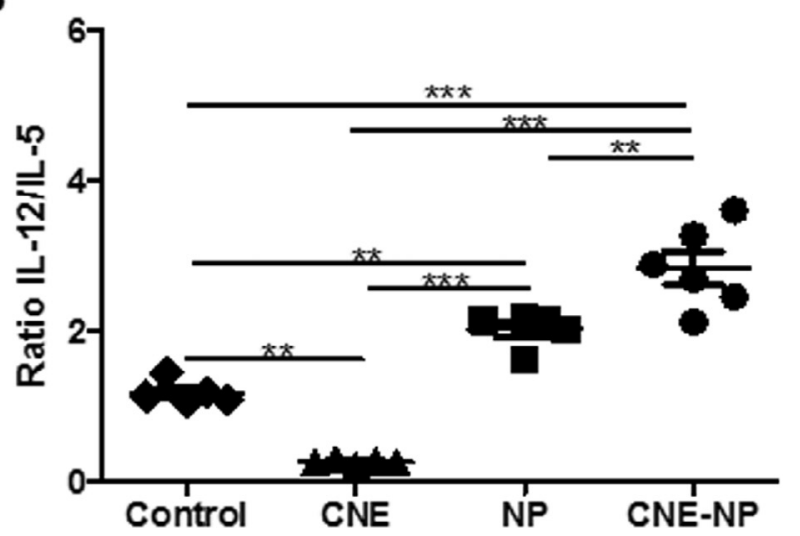

C

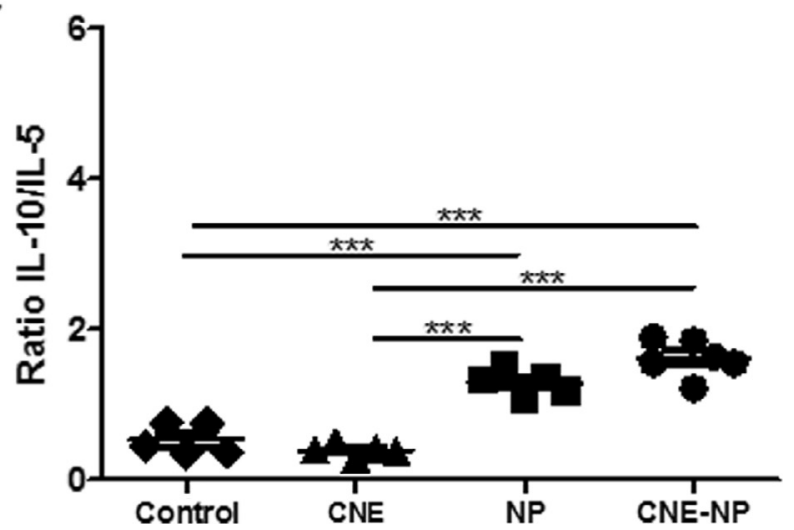

Fig. 8. Pro-Th1 and Pro-Treg response ratios elicited after oral immunization. Th1/Th2 ratio is represented by the ratio IFN-/IL-5 and the ratio IL-12/IL-5 (A and B respectively), whereas Pro-Treg response is represented by the IL10/IL-5 ratio (C). Data are expressed as mean \pm SD. ${ }^{*} \mathrm{p}<0.05 ;{ }^{* * *} \mathrm{p}<0.01 ;{ }^{* * * *} \mathrm{p}<0.001 ;{ }^{* * * * *} \mathrm{p}<0.0001$

the CNE-to-polymer ratio, the mean size of nanoparticles increased (from $194 \mathrm{~nm}$ to $574 \mathrm{~nm}$ ), particularly for the highest ratio tested in which the resulting nanoparticles were not stable. In parallel, the CNEto-polymer ratio increase produced nanoparticles with lower negative zeta potential (from $-46 \mathrm{mV}$ to $-35 \mathrm{mV}$ ). Regarding the payload, the maximum CNE loading was observed when nanoparticles were prepared at a ratio of 0.06; although, encapsulation efficiency was lower than for a CNE-to-polymer ratio of $0.03(62 \%$ vs $80 \%)$. These results are in line with those described by Feczkó and coworkers [27], who evaluated the effect of loading PLGA nanoparticles with bovine serum albumin. In this work, they clearly demonstrated that at low polymer concentration, the increase of a protein cargo caused considerable decrease in the encapsulation efficiency and viceversa. A similar effect has
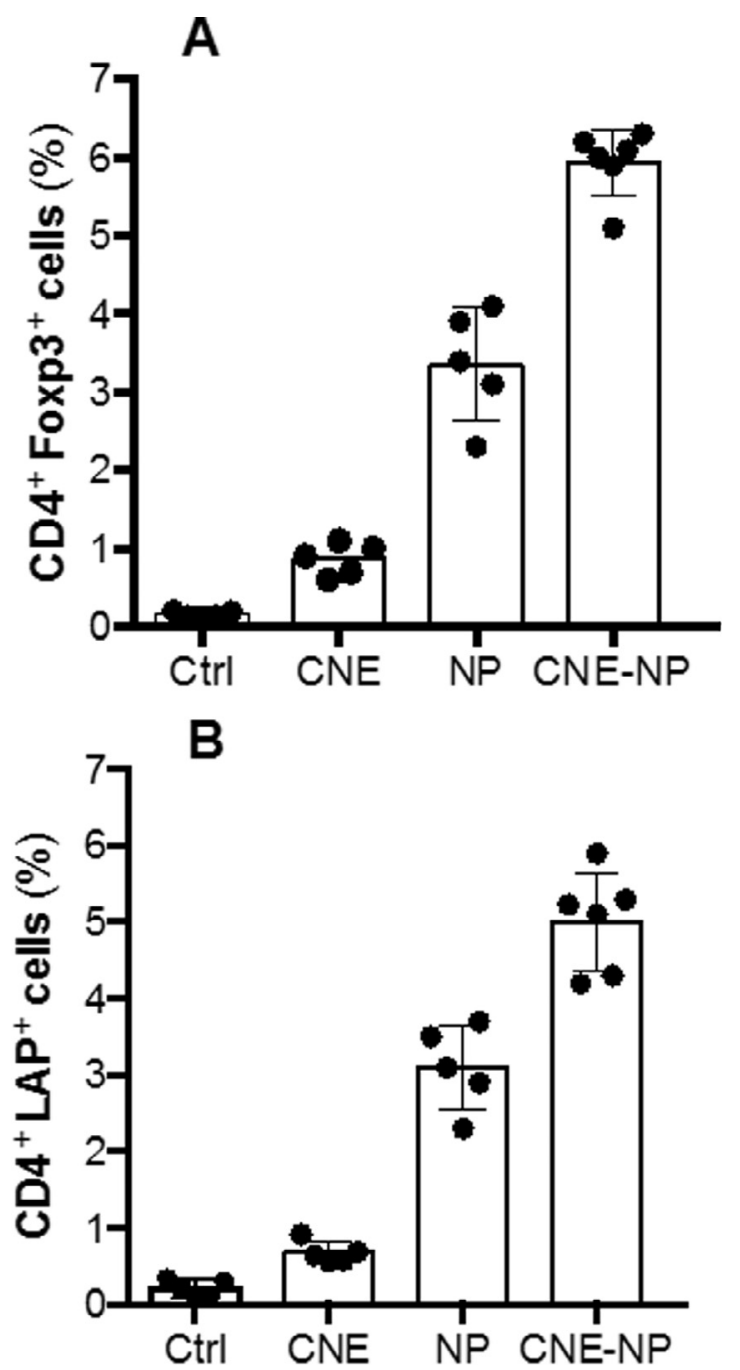

Fig. 9. Nanoparticle formulation containing cashew nut extract increased regulatory $\mathrm{T}$ cells (Tregs) in mice. BALB/c mice ( $n=5-6$ /group) were orally immunized with a single dose of cashew nut extract (CNE), empty nanoparticles (NP) and CNE-loaded nanoparticles (CNE-NP). Five weeks after oral immunization, mice were sacrificed and mesenteric lymph nodes (mLNs) removed. Cells were stained and Treg populations were analyzed by flow cytometry. (A) $\mathrm{CD}^{+}{ }^{+} \mathrm{Foxp}^{+}$and (B) $\mathrm{CD}^{+}{ }^{+} \mathrm{LAP}^{+}$cells were gated on lymphocyte population. Bar graphs are shown as mean $\pm \mathrm{SD} ; n=5$. "p $<0.05$; $\mathrm{p}<0.01 ;{ }^{* * * * *} \mathrm{p}<0.001 ;{ }^{* * * * * *} \mathrm{p}<0.0001$.

been also recently described with the encapsulation of campthotecin in poly(anhydride) nanoparticles [28]. Based on these optimization results, the CNE-to-polymer ratio was fixed in 0.06. Under these experimental conditions ( $30 \mathrm{~min}$ of incubation and a ratio of 0.06), CNE-NP displayed a mean size of $239 \mathrm{~nm}$ with a negative zeta potential of $-38 \mathrm{mV}$ and a CNE payload of $55 \mu \mathrm{g} / \mathrm{mg}$ (Table 2).

\subsection{Characterization of CNE-NP}

In order to confirm the encapsulation of cashew nut proteins and evaluate if the manufacture process of nanoparticles affected the structural integrity and antigenicity of the allergenic proteins, several studies were performed. The protein profile obtained from the analysis of the free CGE was similar to that obtained from CNE-NP (after extraction), with the presence of the three main sensitizing proteins (Ana o 1, Ana o 2, and Ana o 3). The preservation of cashew nut proteins suggested that their association in the nanoparticles did not affect their structure, according to their molecular mass (defined by protein migration pattern in CGE). In addition, immunoblotting confirmed that the encapsulation process did not modify the antigenicity of 
nanoparticle-entrapped cashew nut proteins, exhibiting the same reactive proteins of free CNE. Previous studies reported that cashew nut allergic patients present high sensitization to Ana o $1(\sim 50 \%)$ [29], Ana o $2(\sim 62 \%)$ [30], and Ana o $3(81 \%)$ [8].

The thermograms of free cashew nut extract (CNE), empty nanoparticles (NP) and cashew nut extract loaded nanoparticles (CNE-NP) are shown in Fig. 1A. Free CNE revealed a melting endothermic event between $40^{\circ} \mathrm{C}$ and $60^{\circ} \mathrm{C}$ that corresponded to the melting point of the cashew nut extract, indicating protein denaturation. Campo-Deaño et al. found the same protein denaturation profile when studied the effect of the freeze-drying process in surimi (Dosidicus gigas) protein extracts [31]. The thermogram of empty nanoparticles exhibited an endothermic peak, between $110^{\circ} \mathrm{C}$ and $120^{\circ} \mathrm{C}$, and an exothermic event, between $130^{\circ} \mathrm{C}$ and $150^{\circ} \mathrm{C}$. This profile was similar to the thermogram of Gantrez $^{\circledast}$ AN nanoparticles previously reported by D'Souza and collaborators [32]. Likely, CNE-NP exhibited a similar thermogram than NP, with appearance of a second endothermic event between $205^{\circ} \mathrm{C}$ and $220^{\circ} \mathrm{C}$, suggesting the interaction of CNE and polymer. The disappearance of CNE melting endotherm event in CNENP suggested its protection against protein denaturation at low temperatures. This finding can also be an evidence of the efficient CNE incorporation into poly(anhydride) nanoparticles.

The X-ray diffraction spectra for CNE, NP and CNE-NP are shown in Fig. 1B. CNE exhibited a semi-crystalline nature with one sharp diffraction peak, followed by two amorphous peaks. For NP, as previously reported [33], and CNE-NP, the diffractograms displayed an amorphous profile. The disappearance of the sharp diffraction peak from CNE, when encapsulated in poly(anhydride) nanoparticles, was considered as another important evidence of its efficient encapsulation in nanoparticles.

Fig. 1C shows the overlaid IR spectra of CNE, NP and CNE-NP. The infrared spectrum clearly demonstrates the association of cashew nut proteins to the nanoparticles, as indicated by the following typical bands for CNE present in the nanoparticle spectrum: a broad absorption band at $1516 \mathrm{~cm}^{-1}$ corresponding to the free amino groups of cashew nut proteins [34]. The spectra of CNE-NP also revealed conjugation of free cashew nut proteins with the free carbonyl groups of poly(anhydride) as a reduction in the absorbance peak at $1750 \mathrm{~cm}^{-1}$ [34].

Fig. 2 summarizes the stability studies of nanoparticle formulations (NP and CNE-NP) after their dispersion in simulated gastric (SGF, pH 1.2) and intestinal (SIF, $\mathrm{pH}$ 6.8) fluids at $37^{\circ} \mathrm{C}$. In SGF, NP displayed a lower stability than CNE-NP, as revealed the mean size increase (from about 180 till $275 \mathrm{~nm}$ in $2 \mathrm{~h}$ ) and the important reduction of turbidity of nanoparticle suspensions. On the contrary, under SIF, both types of nanoparticles were importantly affected for the $\mathrm{pH}$ conditions. In both cases, significant changes in the size and turbidity of suspensions were observed. The in vitro release profile of cashew nut proteins from nanoparticles was also evaluated in the same conditions employed for the stability studies of nanoparticles (Fig. 3). Under SGF, about $20 \%$ of the loaded cashew nut extract was released after $2 \mathrm{~h}$. When the nanoparticles were transferred to the SIF, CNE was released from nanoparticles in a continuous way during the 22 following hours. At the end of the experiment $(24 \mathrm{~h}$ ), about $80 \%$ of the total CNE payload in the nanoparticles was released. All of these results, from stability and release studies, may be explained by the particular behavior of poly(anhydride) nanoparticles. In fact, in an aqueous environment the anhydride groups of the polymer may be hydrolyzed (the reaction is favored under neutral/basic $\mathrm{pH}$ conditions), yielding two carboxylic groups $[28,35]$. This hydrolysis phenomenon induces the swelling of nanoparticles, due to the presence of neighboring negative charges of carboxylic acids, and the observed increase in their mean size (Fig. 2). All of this would facilitate the release of the loaded compound and the erosion of nanoparticles by dissolution in an aqueous environment [36].

\subsection{In vitro cell studies}

In vitro cell studies were conducted in Raw cells in which the effect of CNE and CNE-NP on the viability of these cells was evaluated. For all the concentrations tested (10 to $-500 \mu \mathrm{g} / \mathrm{mL}$ ), both NP and CNE-NP increased the metabolic activity of cells (Fig. 4). These results are in agreement with previous observations, in which the capabilities of poly (anhydride) nanoparticles to activate macrophages were described [19]. Interestingly, free cashew proteins induced some toxic effects at the highest concentration tested $(25 \mu \mathrm{g} / \mathrm{mL})$, whereas no negative effects on the activity of cells were observed when nanoparticles containing the same amount of cashew proteins (CNE-NP, $500 \mu \mathrm{g} / \mathrm{mL}$ ) were tested (Fig. 4). In sum, the encapsulation of cashew nut allergens into nanoparticles minimized the toxicity associated to the cashew nut extract, increasing the viability of cells. This effect would be associated to the ability of poly(anhydride) nanoparticles to activate the metabolism of macrophages [19].

On the other hand, and to elucidate the activation consequences on the antigen presenting cells, the effect of free CNE, empty NP or CNENP on the release of pro-inflammatory cytokines (IL- 6 and TNF- $\alpha$ ) by RAW macrophages was evaluated (Fig. 5). CNE (at a concentration of $5 \mu \mathrm{g} / \mathrm{mL}$ ) did not elicit any significant effect on RAW cells. However, both NP and CNE-NP $(100 \mu \mathrm{g} / \mathrm{mL}$ containing aprox. $5 \mu \mathrm{g} \mathrm{CNE} / \mathrm{mL})$ significantly reduced the release of IL- 6 and TNF- $\alpha$ cytokines by cells. This reduction in the release of pro-inflammatory cytokines was similar for both nanoparticle formulations. Thus, for IL-6, NP reduced in $60 \%$ and CNE-NP in $52 \%$ the production of this cytokine. For TNF-alpha, the decrease was of about $46 \%$ for NP, and $42 \%$ for CNE-NP. All of these results demonstrated that the treatment of cells with CNE-NP induced a cell-mediated immune response, which leads to an anti-inflammatory effect, with a reduction of pro-inflammatory cytokines, when compared to the effect produced by free CNE.

\subsection{In vivo studies}

Mice were orally immunized with a single dose of cashew nut extract ( $1 \mathrm{mg} /$ mouse), either free (CNE) or encapsulated in nanoparticles (CNE-NP). Control groups of empty nanoparticles (NP) and non-immunized mice (Control, Ctrl) were also included. Specific IgG2a, IgG1 and IgE were determined by ELISA at days $0,14,28$ and 42 post-immunization (Fig. 6). Results showed that the oral immunization with CNE-NP induced higher levels of both IgG1 and IgG2a (Th2 and Th1 markers, respectively) in comparison with free CNE. In addition, animals immunized with CNE-NP presented lower specific IgE than animals immunized with free CNE (CNE-NP vs. CNE, $p<0.01$ ). Our results evidence that the use of cashew nut proteins encapsulated in poly (anhydride) nanoparticles not only increase, but, most important, modulate the antibody response towards a Th1 anti-allergenic response. These results are in line with previous studies using different formulations of similar poly(anhydride) nanoparticles as adjuvants for immunization purposes $[12,13,18]$.

Further, to explore the T-cell responses, the cytokine secretion profiles were determined after in vitro restimulation of splenocytes from orally immunized mice (Fig. 7). Pro-Th2 cytokines (IL-4, IL-5 and IL13), pro-Th1 cytokines (IL-12 and IFN- $\gamma$ ) and also regulatory cytokines (IL-10) were quantified by ELISA. The levels of pro-Th2 cytokines (IL-4, IL-5 and IL-13) detected in animals immunized with CNE-NP were lower than those who received free CNE proteins (CNE-NP vs. CNE, $p<0.0001$ ). Furthermore, animals immunized orally with either NP or CNE-NP exhibited higher concentrations of IFN- $\gamma$ and IL-12 (Th1 cytokines) than those treated with CNE (CNE-NP vs. CNE, $p<0.0001$; $\mathrm{NP}$ vs. CNE, $p<0.0001$ ). Likewise, mice immunized with CNE-NP showed significant increases in the secretion of IL-10, a key regulatory cytokine in the management of allergy [37], compared with animals treated with free CNE.

One of the major strategies in the discovery of new candidates to an 
effective allergen-specific immunotherapy is to inhibit the Th2 response by the increase of the Th1 one [38]. Oral immunization with CNEloaded nanoparticles not only led to a balanced Th1 and Th2 antibody response, but also induced higher serum levels of IL-10, a T-regulatory cytokine (Fig. 8). IL-10 has been described as an important key factor in the induction of tolerance and, during specific-immunotherapy, modulating isotype response from an IgE to an IgG4 dominated phenotype [39].

Finally, we evaluated the effect of mice oral immunization with CNE-NP ( $1 \mathrm{mg}$ protein) on Tregs cells by measuring the population of $\mathrm{CD}^{+}{ }^{+} \mathrm{Foxp}^{+}{ }^{+}$and $\mathrm{CD} 4{ }^{+} \mathrm{LAP}^{+}$Tregs in the mesenteric lymph nodes (mLNs) (Fig. 9). Six weeks post-immunization, an important increase in $\mathrm{CD}^{+}{ }^{+} \mathrm{Foxp}^{+}{ }^{+}$(Fig. 9A) and $\mathrm{CD} 4{ }^{+} \mathrm{LAP}^{+}$(Fig. 9B) cell frequencies in mLNs was observed six weeks post-immunization. This result is particularly interesting because, as described above, Treg cells development is a key factor involved in the suppression of Th2 responses, reducing allergen specific IgE levels and effector cell activation [40]. From the best of our knowledge, this is the first time that the capability of poly (anhydride) nanoparticles to induce Treg cell expansion after oral administration is demonstrated.

Cashew nut allergens-loaded NPs not only induced a shift in immune response (higher production of pro-Th1 cytokine levels and, consequent reduction of Th2 response), but stimulated the T regulatory cells activation and expansion, promoting a peripheral tolerance to those allergens [22]. In this way, CNE-loaded nanoparticles are a promising approach for management of cashew nut allergy.

\section{Conclusions}

The present work demonstrates that oral administration of cashew nut extract loaded into poly(anhydride) nanoparticles enhanced and modulated both humoral and cellular immune responses. The immunization of animals with these nanoparticles modulated the antibody response towards a Th1 response, decreasing the synthesis of specific IgE. This humoral response was in line with the cytokine secretion profile detected in restimulated splenocites. Thus, this profile was characterized by high levels of pro-Th1 (IL-12 and IFN-g) and regulatory cytokines (IL-10). Last but not least, the oral administration of these nanoparticles significantly increased the populations of Tregs cells. In conclusion, all of these results suggest that the encapsulation of cashew nut allergens into poly(anhydride) nanoparticles may be an approach for cashew nut oral immunization due to their pro-Th1 and $\mathrm{T}$ regulatory properties.

\section{Acknowledgments}

The first author is grateful for Ph.D scholarship and PDSE 6651-15-1 from the Brazilian Education Ministry (CAPES) and Foundation of Research and Technology Development of the State of Pernambuco FACEPE (AMD \#0021-2.00/17). This work was also supported by the Brazilian Ministry of Science and Technology - MCTI (SisNANO/ LARNano-UFPE, CNPq \# 402282/2013-2) and FACEPE (APQ \#03614.03/14).

\section{References}

[1] S.M. Jones, A.W. Burks, Food allergy, N. Engl. J. Med. 377 (2017) 1168-1176.

[2] A.W. Burks, M. Tang, S. Sicherer, A. Muraro, Current perspectives ICON: food allergy, J. Allergy Clin. Immunol. 129 (2012) 906-920.

[3] J.A. Boyce, A. Assa'ad, A.W. Burks, S.M. Jones, H.A. Sampson, R.A. Wood, M. Plaut, S.F. Cooper, M.J. Fenton, Guidelines for the diagnosis and management of food allergy in the United States: report of the NIAID-sponsored expert panel, J. Allergy Clin. Immunol. 126 (2010) S1-S58.

[4] A.T. Clark, K. Anagnostou, P.W. Ewan, Cashew nut causes more severe reactions than peanut: case-matched comparison in 141 children, Allergy Eur. J. Allergy Clin. Immunol. 62 (2007) 913-916.

[5] C.P. Mattison, Y. Bren-Mattison, B. Vant-Hull, A.M. Vargas, R.L. Wasserman, C.C. Grimm, Heat-induced alterations in cashew allergen solubility and IgE binding,
Toxicol. Reports (2016)

[6] F. Wang, S.S. Teuber, S.K. Sathe, P. Tawde, K.H. Roux, Ana o 1, a major cashew nut allergen of the vicilin family, J. Allergy Clin. Immunol. 109 (2002) S163-S163.

[7] F. Wang, J.M. Robotham, S.S. Teuber, S.K. Sathe, K.H. Roux, Ana o 2, a major cashew (Anacardium occidentale L.) nut allergen of the legumin family, Int. Arch. Allergy Immunol. 132 (2003) 27-39.

[8] J.M. Robotham, F. Wang, V. Seamon, S.S. Teuber, S.K. Sathe, H.A. Sampson, K. Beyer, M. Seavy, K.H. Roux, Ana o 3, an important cashew nut (Anacardium occidentale L.) allergen of the 2 S albumin family, J. Allergy Clin. Immunol. 115 (2005) 1284-1290.

[9] D.I. Bernstein, T. Epstein, K. Murphy-Berendts, G.M. Liss, Surveillance of systemic reactions to subcutaneous immunotherapy injections: year 1 outcomes of the ACAAI and AAAAI Collaborative study, Ann. Allergy, Asthma Immunol. 104 (2010) 530-535.

[10] S.R. Roy, J.R. Sigmon, J. Olivier, J.E. Moffitt, D.A. Brown, G.D. Marshall, Increased frequency of large local reactions among systemic reactors during subcutaneous allergen immunotherapy, Ann. Allergy. Asthma Immunol. 99 (2007) 82-86.

[11] H.S. Amin, G.M. Liss, D.I. Bernstein, Evaluation of near-fatal reactions to allergen immunotherapy injections, J. Allergy Clin. Immunol. 117 (2006) 169-175.

[12] C. Gamazo, C. D'Amelio, G. Gastaminza, M. Ferrer, J.M. Irache, Adjuvants for allergy immunotherapeutics, Hum. Vaccines Immunother. 13 (2017) 2416-2427.

[13] H. Pohlit, I. Bellinghausen, H. Frey, J. Saloga, Recent advances in the use of nanoparticles for allergen-specific immunotherapy, Allergy 1461-1474 (2017).

[14] C. Gamazo, G. Gastaminza, M. Ferrer, M.L. Sanz, J.M. Irache, Nanoparticle basedimmunotherapy against allergy, Immunotherapy 6 (2014) 885-897.

[15] R.A. Maldonado, R.A. LaMothe, J.D. Ferrari, A.-H. Zhang, R.J. Rossi, P.N. Kolte, A.P. Griset, C. O’Neil, D.H. Altreuter, E. Browning, L. Johnston, O.C. Farokhzad, R. Langer, D.W. Scott, U.H. von Andrian, T.K. Kishimoto, Polymeric synthetic nanoparticles for the induction of antigen-specific immunological tolerance, Proc. Natl. Acad. Sci. USA 112 (2015) E156-E165.

[16] A. Duschl, Nanoparticles and Allergy, in: D. Boraschi, A. Duschl (Eds.), Nanoparticles Immune Syst. Saf. Eff., 1st Editio, Academic Press, Cambridge, Massachusetts, EUA, 2013, pp. 55-68.

[17] J. De S. Rebouças, J.M. Irache, A.I. Camacho, G. Gastaminza, M.L. Sanz, M. Ferrer, C. Gamazo, Immunogenicity of peanut proteins containing poly(anhydride) nanoparticles, Clin. Vaccine Immunol. 21 (2014) 1106-1112.

[18] S. Gómez, C. Gamazo, B. San Roman, A. Grau, S. Espuelas, M. Ferrer, M.L. Sanz J.M. Irache, A novel nanoparticulate adjuvant for immunotherapy with Lolium perenne, J. Immunol. Methods 348 (2009) 1-8.

[19] J.M. Irache, M. Huici, M. Konecny, S. Espuelas, M.A. Campanero, P. Arbos, Bioadhesive properties of Gantrez nanoparticles, Molecules 10 (2005) 126-145.

[20] G. Ciprandi, G.L. Marseglia, M.A. Tosca, Allergen-specific immunotherapy: an update on immunological mechanisms of action, Monaldi Arch. Chest Dis. 65 (2016) 265-272.

[21] C. Montealegre, M.C. García, C. Del Río, M.L. Marina, C. García-Ruiz, Separation of olive proteins by capillary gel electrophoresis, Talanta 97 (2012) 420-424.

[22] H.H. Salman, C. Gamazo, P.C. De Smidt, G. Russell-Jones, J.M. Irache, Evaluation of bioadhesive capacity and immunoadjuvant properties of vitamin B12-Gantrez nanoparticles, Pharm. Res. 25 (2008) 2859-2868.

[23] C. Gamazo, H. Bussmann, S. Giemsa, A.I. Camacho, D. Unsihuay, N. Martín-Arbella J.M. Irache, Interactions of poly (anhydride) nanoparticles with macrophages in light of their vaccine adjuvant properties, Int. J. Pharm. 496 (2015) 922-930.

[24] M. Mueller, D. Weinmann, S. Toegel, W. Holzer, F.M. Unger, H. Viernstein, Compounds from Caesalpinia sappan with anti-inflammatory properties in macrophages, Food Func. 2 (2016) 1671-1679.

[25] S. Gómez, C. Gamazo, B. San Roman, C. Vauthier, M. Ferrer, J.M. Irachel, Development of a novel vaccine delivery system based on Gantrez nanoparticles, J. Nanosci. Nanotechnol. 6 (2006) 3283-3289.

[26] H.H. Salman, C. Gamazo, M.A. Campanero, J.M. Irache, Salmonella-like bioadhesive nanoparticles, J. Control. Release 106 (2005) 1-13.

[27] T. Feczkó, J. Tóth, G. Dósa, J. Gyenis, Optimization of protein encapsulation in PLGA nanoparticles, Chem. Eng. Process. Process Intensif. 50 (2011) 757-765.

[28] J. Huarte, S. Espuelas, Y. Lai, B. He, J. Tang, J.M. Irache, Oral delivery of camptothecin using cyclodextrin/poly(anhydride) nanoparticles, Int. J. Pharm. 506 (2016) 116-128.

[29] F. Wang, J.M. Robotham, S.S. Teuber, P. Tawde, S.K. Sathe, K.H. Roux, Ana o 1, a cashew (Anacardium occidental) allergen of the vicilin seed storage protein family, J. Allergy Clin. Immunol. 110 (2002) 160-166.

[30] J.M. Robotham, L. Xia, L.N. Willison, S.S. Teuber, S.K. Sathe, K.H. Roux, Characterization of a cashew allergen, 11 s globulin (Ana o 2), conformational epitope, Mol. Immunol. 47 (2010) 1830-1838.

[31] L. Campo-Deaño, C.A. Tovar, J. Borderías, F. Fernández-Martín, Gelation process in two different squid (Dosidicus gigas) surimis throughout frozen storage as affected by several cryoprotectants: thermal, mechanical and dynamic rheological properties, J. Food Eng. 107 (2011) 107-116.

[32] A.A. D'Souza, P. Jain, C.N. Galdhar, A. Samad, M.S. Degani, P.V. Devarajan, Comparative in silico-in vivo evaluation of ASGP-R ligands for hepatic targeting of curcumin gantrez nanoparticles, AAPS J. 15 (2013) 696-706.

[33] P.V. Date, A. Samad, P.V. Devarajan, Freeze thaw: a simple approach for prediction of optimal cryoprotectant for freeze drying, AAPS PharmSciTech. 11 (2010) 304-313.

[34] L. León-Rodríguez, A. Luzardo-álvarez, J. Blanco-Méndez, J. Lamas, J. Leiro, A vaccine based on biodegradable microspheres induces protective immunity against scuticociliatosis without producing side effects in turbot, Fish Shellfish Immunol. 33 (2012) 21-27.

[35] G. Garnier, M. Duskova-Smrckova, R. Vyhnalkova, T.G.M. van de Ven, J.-F. Revol, 
Association in solution and adsorption at an air-water interface of alternating copolymers of maleic anhydride and styrene, Langmuir 16 (2000) 3757-3763.

[36] K. Vandamme, V. Melkebeek, E. Cox, P. Adriaensens, S. Van Vlierberghe,

P. Dubruel, C. Vervaet, J.P. Remon, Influence of polymer hydrolysis on adjuvant effect of Gantrez-AN nanoparticles: implications for oral vaccination, Eur. J. Pharm. Biopharm. 79 (2011) 392-398.

[37] C.A. Akdis, M. Akdis, Mechanisms and treatment of allergic disease in the big picture of regulatory T cells, J. Allergy Clin. Immunol. 123 (2009) 735-746.

[38] M. Jutel, I. Agache, S. Bonini, A.W. Burks, M. Calderon, W. Canonica, L. Cox,
P. Demoly, A.J. Frew, R. O'Hehir, J. Kleine-Tebbe, A. Muraro, G. Lack, D. Larenas, M. Levin, H. Nelson, R. Pawankar, O. Pfaar, R. Van Ree, H. Sampson, A.F. Santos, G. Du Toit, T. Werfel, R. Gerth Van Wijk, L. Zhang, C.A. Akdis, International consensus on allergy immunotherapy, J. Allergy Clin. Immunol. 136 (2015) 556-568.

[39] A. Nowak-Wegrzyn, S. Albin, Oral immunotherapy for food allergy: mechanisms and role in management, Clin. Exp. Allergy 45 (2015) 368-383.

[40] P.L. Smaldini, M.L.O. Delgado, C.A. Fossati, G.H. Docena, Orally-induced intestinal $\mathrm{CD} 4+\mathrm{CD} 25+$ FoxP3 + treg controlled undesired responses towards oral antigens and effectively dampened food allergic reactions, PLoS One 10 (2015) 1-14. 